\title{
GM debate must go global, says meeting...
}

\section{Edinburgh}

A permanent international forum should be set up to assess both the science and the social implications of genetically modified (GM) foods, according to key scientists at a meeting last week organized by the Organisation for Economic Co-operation and Development (OECD).

Leaders of the world's eight largest industrial nations (the G8 nations) are likely to be asked to endorse a proposal to create an appropriate panel.

The panel, proposed by Sir John Krebs, chairman of Britain's new Food Standards Agency, would be conceptually similar to the Intergovernmental Panel on Climate Change (IPCC), which looks at the science and implications of global warming.

Last year, the G8 heads of state asked the OECD to address the issue of health and scientific aspects of GM foods, after hearing demands for a moratorium on the commercial planting of GM crops before safety had been properly assessed.

"Such a mechanism, intended to inform politics in the future, must be firmly grounded in science," says Krebs, who chaired the Edinburgh meeting. "But it must go beyond the science. And it needs to be an international body because we are dealing with a global issue; whether or not consumers in one particular country reject

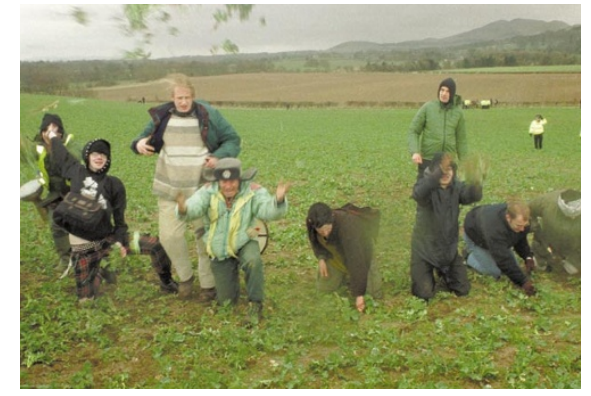

Emotive produce: protesters uproot GM plants.

GM foods, their development is already going ahead in several countries."

Sir Robert May, the UK government's chief scientific adviser, said that, just as the IPCC had been "very helpful" in the climate debate, something similar was needed on the GM issue.

"You need a mechanism for delineating the landscape, and for identifying things that we agree on and things that we do not agree on. An international panel would be a first step along this road," says May.

Participants on both sides of the debate have cautiously welcomed the proposal. Paul Muys, a spokesman for the European Association for BioIndustries, said his group was "inclined to see this in a positive way".

"Our approach is that everything should

be science-based," said Muys. "But there are other non-scientific issues that need to be dealt with as well."

Environmental groups present at the Edinburgh meeting were equally cautious, seeing potential value in an international panel able to assess the current state of scientific knowledge. But they were also concerned that it should not be sciencedriven, but start from a broader social agenda.

"Krebs has described such a panel as being 'science plus'," said Benedikt Haerlin, coordinator of Greenpeace International's Genetic Engineering Campaign. "But attempts to say scientists should decide which way to go has led us into just the situation that we now face. The forum should be based on a 'people plus science' approach; that is completely different."

If the idea is endorsed at the G8 summit in July, a key issue needing to be addressed is who should organize such an international panel. One leading candidate would be the OECD itself, which has been responsible for a series of studies and reports on the safety and regulatory aspects of biotechnology in recent years.

But such a prospect received a cool reaction from the environmental groups present. Peter Riley, for example, food campaigner for Friends of the Earth, expressed concern that the OECD - whose activities many still see as reflecting the views of the industrial community - has no tradition of giving non-governmental organizations a significant role in its deliberations.

Suman Sahi, president of the Gene Campaign in India, was equally sceptical. "We have had very bitter experiences with international forums," she said. "We have seen what happened with the [World Trade Organization]. If there is to be any internationalism on this issue, it has to come after discussion with the developing countries that have a view on the matter."

Another large question mark is the likely attitude of the United States. US officials are reluctant to make any public comment until the proposal has been developed further But just as the IPCC has come under fire from US energy companies, many in the US life-science industry are thought to have reservations about the creation of any international panel that might legitimate tighter regulation of their activities.

One main point of agreement to emerge from the conference, however, according to a report presented to the final session by the meeting's rapporteurs (see box, left), was the need for "openness and transparency" in the policy process. Even the critics of GM food accepted that a global panel might be a risk, they need to be kept under review.

Sir John Krebs, who chaired

step in this direction. 